\title{
Correction to: Phonological and graphotactic influences on spellers' decisions about consonant doubling
}

\author{
Rebecca Treiman $^{1} \cdot$ Sloane Wolter ${ }^{1}$
}

Published online: 17 July 2018

(C) Psychonomic Society, Inc. 2018

\section{Correction to: Mem Cogn \\ https://doi.org/10.3758/s13421-018-0793-9}

Please note that, because of an error in the production process, many of the International Phonetic Alphabet symbols were missing from the originally published pdf version of the article, both in the main text and in the Appendix. The error has been fixed and the pdf version of the article now includes the correct symbols.

The online version of the original article can be found at https://oi.org/ 10.3758/s13421-018-0793-9

\section{Rebecca Treiman} rtreiman@wustl.edu

1 Department of Psychological and Brain Sciences, Washington University in St. Louis, Campus Box 1125, St. Louis, MO 63130, USA 